\title{
Physiotherapeutic stimulation: Early prevention of lymphedema following axillary lymph node dissection for breast cancer treatment
}

\author{
ALMIR JOSÉ SARRI ${ }^{1}$, SONIA MARTA MORIGUCHI ${ }^{2}$, ROGÉRIO DIAS ${ }^{5}$, STELA VERZINHASSE PERES ${ }^{4}$, \\ EDUARDO TINÓIS DA SILVA ${ }^{2}$, KÁTIA HIROMOTO KOGA ${ }^{6}$, ÂNGELO GUSTAVO ZUCCA MATTHES ${ }^{3}$, \\ MARCELO JOSÉ DOS SANTOS ${ }^{2}$, EUCLIDES TIMÓTEO DA ROCHA ${ }^{2}$ and RAPHAEL LUIZ HAIKEL ${ }^{3}$ \\ Departments of ${ }^{1}$ Physiotherapy, ${ }^{2}$ Nuclear Medicine, and ${ }^{3}$ Mastology, Barretos Cancer Hospital; \\ ${ }^{4}$ Center for Researcher Support, Barretos Cancer Hospital; Departments of ${ }^{5}$ Obstetrics and Gynecology, and \\ ${ }^{6}$ Nuclear Medicine, Botucatu Medical School, São Paulo State University (UNESP), São Paulo, Brazil
}

Received August 17, 2009; Accepted October 8, 2009

DOI: $10.3892 /$ etm_00000024

\begin{abstract}
The aim of this study was to confirm the effectiveness of early physiotherapeutic stimulation for lymphatic flow progression in patients with breast cancer undergoing axillary dissection. This was a randomized experimental study on 22 patients who underwent lymphoscintigraphy in their arms on two different occasions, firstly without stimulation and secondly after randomization into two groups: without physiotherapeutic stimulation (WOPS; n=10) and with physiotherapeutic stimulation (WPS; $n=12$ ). The lymphoscintigraphy scan was performed with ${ }^{99 \mathrm{~m} T c-p h y t a t e}$ administered into the second interdigital space of the hand, ipsilaterally to the dissected axilla, in three phases: dynamic, static, and delayed whole body imaging. Physiotherapeutic stimulation was carried out using Földi's technique. In both groups, images from the two examinations of each patient were compared. Flow progression was considered positive when, on the second examination, the radiopharmaceutical reached areas more distant from the injection site. Statistical analysis was used to evaluate frequencies, percentages and central trend measurements, and non-parametric tests were conducted. Descriptive analysis showed that the WPS and WOPS groups were similar in terms of mean age, weight, height, body mass index and number of lymph nodes removed. There were statistically significant associations between physiotherapeutic stimulation and radiopharmaceutical progression at all three phases of the study $(\mathrm{p}<0.0001)$. Early physiotherapeutic stimulation in breast cancer patients undergoing radical axillary dissection is effective, and can therefore be indicated as a preventive measure against lymphedema.
\end{abstract}

Correspondence to: Dr Almir José Sarri, Department of Physiotherapy, Barretos Cancer Hospital, Avenida 25, no. 923, CEP 14780-330, Centro Barretos, São Paulo, Brazil

E-mail: almirsarri@hotmail.com

Key words: preventive physiotherapy, lymphoscintigraphy, lymphedema

\section{Introduction}

Breast cancer is one of the most frequent causes of mortality among women, with a high incidence in both developed and developing countries $(1,2)$. Fifty percent of breast cancer cases are diagnosed at an advanced stage and include lymph node metastatic infiltration, necessitating more aggressive and costly treatment (3) and increasing the risk of post-treatment complications (4-8).

Aggressive surgery in advanced stage breast cancer cases interrupts the main lymphatic drainage route in the upper limbs and is the most important factor in the formation of lymphedema (5). The pathogenesis of post-mastectomy lymphedema associated with axillary dissection is in particular attributed to the small number of lymphatic vessels in the dissected area $(9,10)$. According to Glass et al, the more extensive the axillary dissection, the greater the risk of complications (11).

Once lymphedema has become established, it is incurable. Neither surgical nor drug treatments for lymphedema have shown success $(12,13)$. However, lymphedema can be avoided, treated and controlled with daily preventive measures (14). The prevention of lymphedema has been attempted using intraoperative techniques that take a more conservative approach towards the axillary chain, such as the investigation of the sentinel lymph nodes. Through this, selective resection that is safe and less mutilating becomes possible, with satisfactory results, although it is limited to patients without evidence of lymph node macrometastasis (5,7,15-17).

Preventive measures, such as lymphatic self-massage, hydration, kinesiotherapy, manual lymphatic drainage and the use of elastic compression armbands, have been gaining increasing attention $(12,18)$. None is more important than the others, but used together they may be effective in controlling and preventing lymphedema. The only requirement is that the patient must be taught how to carry out the procedures on a daily basis (18-21). Self-massage, also known as simple manual lymphatic drainage, is a version of manual lymphatic drainage in which the patient learns the procedure and is able 
to perform it alone, at home. It involves a series of gentle circular movements, starting with stimulation of the axillary lymph node chain contralateral to the surgical manipulation and of the inguinal chain homolateral to the surgical manipulation. This is followed by gentle movements at a site distant from the area of congestion, moving gradually towards the swollen limb $(12,18,22,23)$.

Lymphoscintigraphy is an effective technique for evaluating the lymphatic systems of the upper and lower limbs $(5,24,25)$. It provides functional information regarding drainage and obstruction in this system, with details on the morphology of the lymph vessels and lymph nodes (26). In relation to lymphedema following radical mastectomy, lymphoscintigraphy has only been used to assess lymphedema that has already become established. In such cases, it is performed before and after physiotherapy (26-29) in order to investigate the effectiveness of the therapy.

This study was inspired by the notion that the prevention of lymphedema is the most effective way to diminish morbidity, and that physiotherapeutic measures should begin as early as possible for breast cancer patients undergoing axillary dissection. It was in particular motivated by the scarcity of the literature on the subject, and aimed to evaluate the effectiveness of early physiotherapeutic stimulation on lymph flow progression in these breast cancer patients.

\section{Materials and methods}

This randomized experimental study included 22 women who underwent radical mastectomy or quadrantectomy associated with ipsilateral axillary lymph node dissection between 2005 and 2008. Patients were over 18 years of age and had unilateral breast cancer. They were seen between 15 and 60 days after surgery, and presented arm range of motion corresponding to more than $120^{\circ}$ of shoulder flexion. Patients were excluded if they had undergone previous chemotherapy or radiotherapy, if they were known to have had lymphatic disease prior to the axillary dissection, if they presented inflammatory or infectious processes associated with the upper limb, or if the lymphoscintigraphy results could not be analyzed.

Patients gave their free and informed consent for participation in the study. The study was approved by the Research Ethics Committee of Barretos Cancer Hospital.

The 22 patients underwent two lymphoscintigraphy examinations, for a total of 44 procedures. The first examination on each patient was performed between 15 and 60 days after surgery. This was considered to be a control examination, and was performed without physiotherapeutic stimulation. The second examination was performed $7 \pm 3$ days after the first. For this second examination, the patients were randomized into two groups: the 'with physiotherapeutic stimulation' (WPS) group, in which patients received physiotherapeutic stimulation while the lymphoscintigraphy examination was being conducted, and the 'without physiotherapeutic stimulation' (WOPS) group, in which patients received an examination under conditions similar to the first.

Physiotherapeutic stimulation. Physiotherapeutic stimulation lasted for $5 \mathrm{~min}$, from the 5 th to the 10th $\mathrm{min}$ of the dynamic phase of the second examination in the randomized

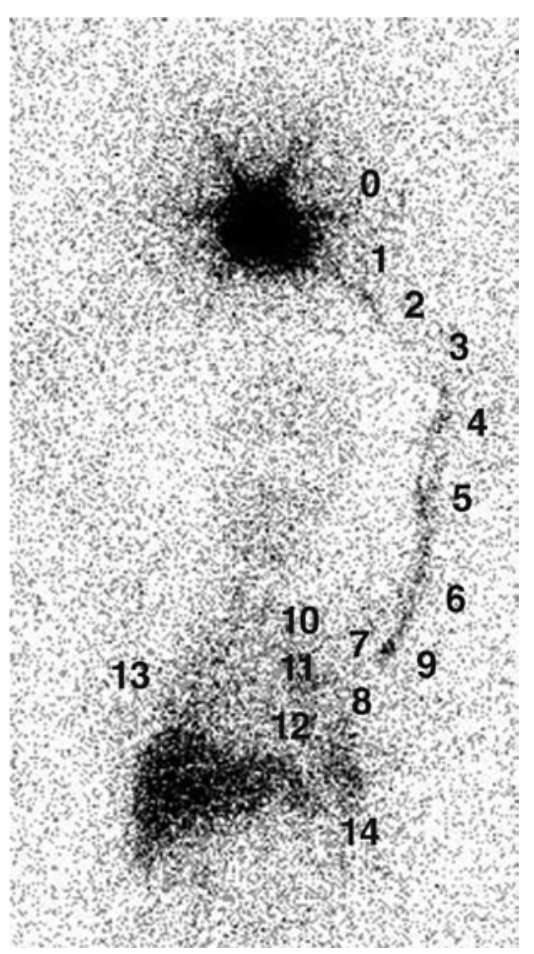

Figure 1. Qualitative analysis: sequential ordinal classification of upper limb. 0 , injection site; 1 , distal third of forearm; 2 , middle third of forearm; 3 , proximal third of forearm; 4, distal third of upper arm; 5, middle third of upper arm; 6, proximal third of upper arm; 7, axilla without lymph nodes; 8 , axillary lymph nodes; 9 , lymph nodes in dorsolateral part of upper arm; 10, apical lymph nodes; 11, central lymph nodes; 12 , internal thoracic lymph nodes; 13 , lymph nodes in contralateral axilla; 14 , spleen.

WPS group. It was performed by a single physiotherapist in accordance with the technique proposed by Földi (23), with stimulation of the contralateral axillary lymph node chain and homolateral inguinal chain relative to the manipulated breast and axilla using circular movements with the palms of the hand to lightly and gently move the skin.

Lymphoscintigraphy. Lymphoscintigraphy was performed using a two-head gamma camera (GE Millennium VG Hawkeye) with a low-energy high-resolution collimator, photopeak centered on $140 \mathrm{KeV}$, windows of $20 \%$ and matrices of $128 \times 128$ for dynamic images, $256 \times 256$ for static images and 256x1024 for the whole body scan, without magnification. Patients were positioned in dorsal decubitus with their arms raised above their head, then $37 \mathrm{MBq}$ of ${ }^{99 \mathrm{~m}} \mathrm{Tc}$-phytate in a volume of $0.5 \mathrm{ml}$ was administered subcutaneously using an insulin needle and syringe in a fan-shaped injection into the second interdigital space (25-27) of the manipulated limb. Capture of dynamic images with a 1 min exposure was initiated immediately after the injection and continued for $20 \mathrm{~min}$. Two static images with a $500 \mathrm{sec}$ exposure were acquired immediately after the end of the dynamic examination, one in the same field of view as the dynamic examination, including the area from the hands to the axillae, and the other including the anterior thoracic region and axillae. A whole body scan at a velocity of $7 \mathrm{~cm} / \mathrm{sec}$ over the bed was initiated 90 min after the injection of radioactive fluid and included anterior and posterior projections, with the patient in the same position. 

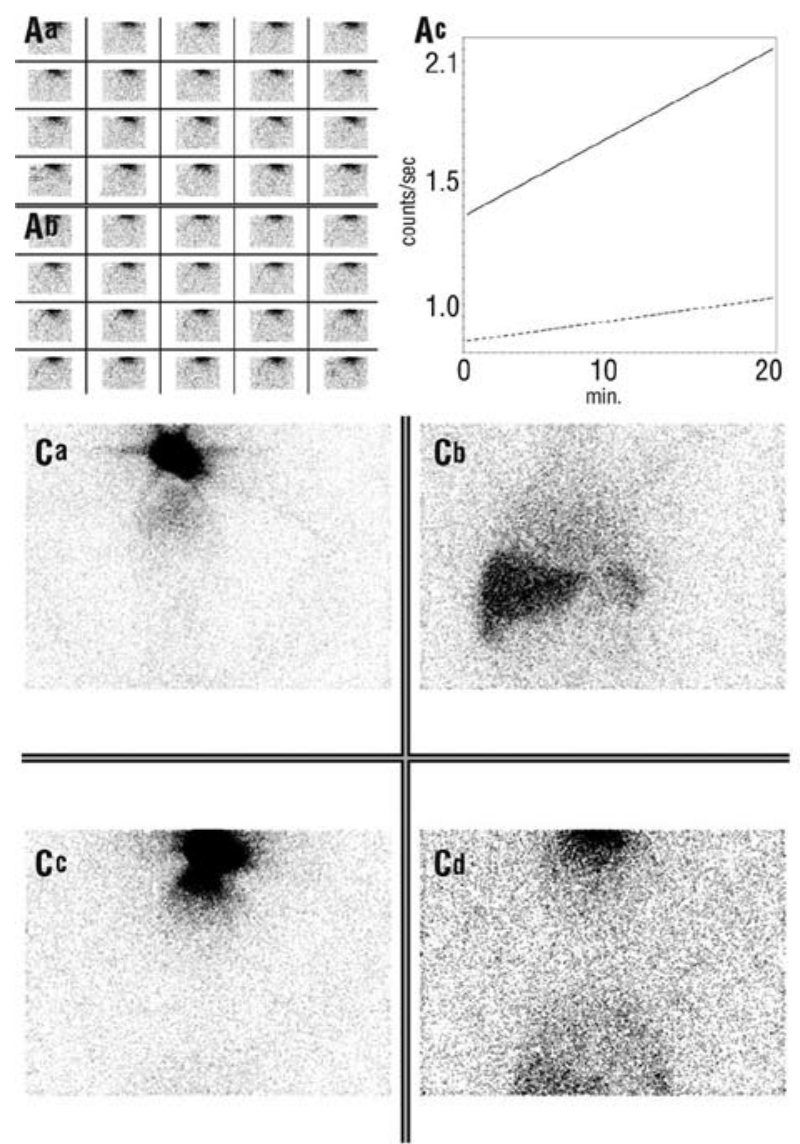

\begin{tabular}{|c|c|c|c|c|}
\hline a & & 7 & $r$ & \\
\hline$r$ & $\pi$ & 7 & 7 & $\pi$ \\
\hline 7 & 7 & $\pi$ & 7 & 7 \\
\hline 7 & 7 & 7 & 7 & 7 \\
\hline B6 & 7 & s & $\%$ & r \\
\hline$\approx$ & $\pi$ & $\sigma$ & $r$ & $\rho$ \\
\hline$\sigma$ & $r$ & $n$ & $r$ & $\pi$ \\
\hline$\rho$ & $m$ & $\sigma$ & $m$ & $\pi$ \\
\hline
\end{tabular}
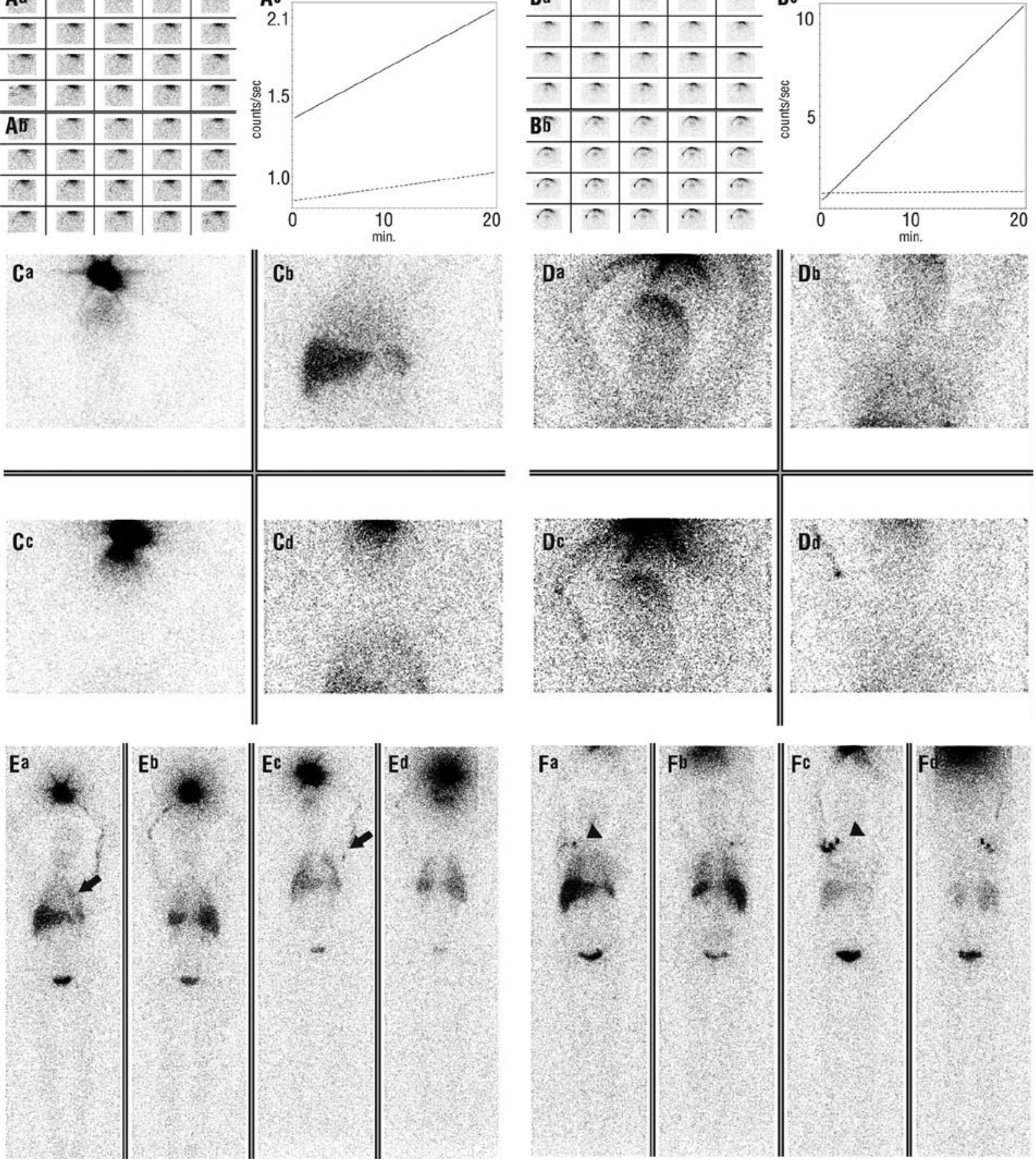

Figure 2. Lymphoscintigraphy of the WOPS group (left) and WPS group (right) showing the three phases of examination. (A and B) Dynamic images of the first (a) and second (b) examination with linear derivation graph (c). (C and D) Static images of the arms (a) and thoracic region (b) from the first examination, and of the arms (c) and thoracic region (d) from the second examination. (E and F) Whole body scan, anterior (a) and posterior (b) from the first examination, and anterior (c) and posterior (d) from the second examination. In the WOPS group, no progression between the two examinations was observed. The arrival of the radiopharmaceutical in the axillary region was only apparent in the whole body scan (E) (arrow). There was no evidence of velocity variation in lymphatic flow (Ac). In the WPS group, lymphatic progression was observed in the three phases of the examination, with arrival of radiopharmaceutical in the axilla in the dynamic $(\mathrm{Bb})$ and the static ( $\mathrm{Dc}$ and $\mathrm{d})$ phase. More lymph nodes were identified in the whole body scan from the second examination ( $\mathrm{Fc}$ and d) (arrowhead), with linear derivation showing increased lymphatic flow velocity after physiotherapeutic stimulation $(\mathrm{Bc})$.

Patients attended the lymphoscintigraphy procedure wearing clothes that would not restrict the superficial lymphatic circulation, and were instructed not to perform any activity with the limb until the end of the examination.

Qualitative analysis. Images from the dynamic, static, and whole body scan phases of the first and second examinations performed on each patient were paired. The area reached by the radioactive fluid in the lymphatic vessels of the upper limb, and the sites and numbers of lymph nodes viewed in the three phases of lymphoscintigraphy acquisition, were respectively compared. A sequential ordinal classification for the area reached by the radiopharmaceutical was applied from the injection point to the most distant point reached using a scale of 0-14 (Fig. 1) (30). 
Table I. Lymphatic flow progression in the WPS and WOPS groups categorized according to phase.

\begin{tabular}{|c|c|c|c|}
\hline & WPS & WOPS & \\
\hline Progression & No. $(\%)$ & No. $(\%)$ & P-value \\
\hline Dynamic images $^{a}$ & & & $<0.001$ \\
\hline Yes & $10(100)$ & $0(0.00)$ & \\
\hline No & $0(0.00)$ & $9(100)$ & \\
\hline Static images ${ }^{\mathrm{a}}$ & & & $<0.001$ \\
\hline Yes & $11(100)$ & $0(0.00)$ & \\
\hline No & $0(0.00)$ & $8(100)$ & \\
\hline Whole body scan ${ }^{\mathrm{a}}$ & & & $<0.001$ \\
\hline Yes & $11(91.7)$ & $0(0.00)$ & \\
\hline No & $1(8.30)$ & $7(100)$ & \\
\hline Total & $12(100)$ & $10(100)$ & \\
\hline
\end{tabular}

aSome values were not determined. ${ }^{b}$ Fisher's exact test.

Patients were considered to present positive progression of lymphatic flow if the area reached by the radioactive fluid in the second examination was further from the injection point than that reached in the first examination, or when the number of lymph nodes apparent in the second examination was greater than in the first examination.

Quantitative analysis in the dynamic phase. Identical rectangular areas of interest were created and laid out in the proximal region of the arm that received the injection and the contralateral arm of each patient in both examinations. Activity veresus time curves were generated for these areas. The contralateral arm was taken to be the background.
Angular coefficients were obtained directly from processing performed by the equipment. A value of 0.00005 was taken for every angular coefficient calculated to have a value of 0.0000 by the equipment. To determine the net coefficient for physiotherapeutic stimulation, the background coefficient was subtracted from the coefficient of the arm that received the injection. The velocity of the progression of lymphatic fluid was represented by the net angular coefficient. Analysis of the velocity of the progression of lymphatic flow was performed by comparing the net angular coefficients of the straight lines from both examinations on the same patient. Positive progression was determined when there was a higher velocity in the second examination than in the first (Fig. 2).

Statistical analysis. Frequencies, percentages, central trend measurements and dispersion measurements were used to characterize the sample. The Kolmogorov-Smirnov test was used to investigate whether the sample had normal distribution. Since it was found that it did not, non-parametric tests were applied. The Mann-Whitney test was used to evaluate differences between the means of the quantitative variables of the WPS and WOPS groups. Fisher's exact test was used to evaluate the association between the progression of lymphatic drainage and the presence of physiotherapeutic stimulation. Wilcoxon's non-parametric test was used to investigate the number of lymph nodes observed before and after physiotherapeutic stimulation in each group. For all the analyses, the level of significance was set at $5 \%$.

\section{Results}

Among the 22 patients studied, 12 were in the group which received physiotherapeutic stimulation (WPS) and 10 were in the group which did not (WOPS). The two groups were homogenous in terms of the medians of the variables: age in years (47.5 vs. 52.0 ; $\mathrm{p}=0.198$ ), weight in kilograms (65.6 vs.

Table II. Number of lymph nodes apparent in the first and second examination in the WPS and WOPS groups. ${ }^{a}$

\begin{tabular}{|c|c|c|c|c|c|c|c|c|c|}
\hline \multirow[t]{2}{*}{ Variable } & \multicolumn{4}{|c|}{ First examination } & \multicolumn{4}{|c|}{ Second examination } & \multirow[t]{2}{*}{ P-value ${ }^{b}$} \\
\hline & No. & Mean (SD) & Median & Min-Max & No. & Mean (SD) & Median & Min-Max & \\
\hline WPS & 11 & $2.1(1.7)$ & 2.0 & $0-6$ & 11 & $3.7(2.1)$ & 4.0 & $0-7$ & 0.007 \\
\hline WOPS & 7 & $2.6(2.0)$ & 3.0 & $0-5$ & 7 & $1.9(1.6)$ & 2.0 & $0-4$ & 0.102 \\
\hline
\end{tabular}

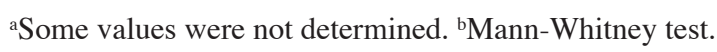

Table III. Descriptive statistics on the variable of the ratio between the angular coefficients after/before stimulation for the WOPS and WPS groups. ${ }^{\mathrm{a}}$

\begin{tabular}{lrrrrrr}
\hline Group & No. & Mean & Median & Variance & Standard deviation & Min-Max \\
\hline WPS & 10 & 44.0 & 2.75 & 6232.3 & 78.9 & $0.17-240$ \\
WOPS & 8 & 0.8 & 0.75 & 0.5 & 0.7 & $0.08-2$ \\
\hline
\end{tabular}

aSome values were not determined. 
Table IV. Descriptive statistics on the drainage bundles of the upper limbs. ${ }^{\text {a }}$

\begin{tabular}{|c|c|c|c|c|}
\hline & \multicolumn{2}{|c|}{ WPS } & \multicolumn{2}{|c|}{ WOPS } \\
\hline & $\begin{array}{l}\text { First examination } \\
\text { no. }(\%)\end{array}$ & $\begin{array}{c}\text { Second examination } \\
\text { no. }(\%)\end{array}$ & $\begin{array}{l}\text { First examination } \\
\text { no. }(\%)\end{array}$ & $\begin{array}{c}\text { Second examination } \\
\text { no. }(\%)\end{array}$ \\
\hline Bundles not shown & $6(50.0)$ & 0 & $4(50.0)$ & $6(75.0)$ \\
\hline Basilic lymphatic bundle & 0 & 0 & $1(12.5)$ & 0 \\
\hline Cephalic lymphatic bundle & $4(33.3)$ & $9(75.0)$ & $3(37.5)$ & $1(12.5)$ \\
\hline Both bundles shown & $2(16.7)$ & $3(25.0)$ & 0 & $1(12.5)$ \\
\hline Total & $12(100)$ & $12(100)$ & $8(100)$ & $8(100)$ \\
\hline
\end{tabular}

a Some values were not determined.

64.2; $\mathrm{p}=0.373)$, height in meters ( 1.60 vs. $1.52 ; \mathrm{p}=0.080)$, body mass index in $\mathrm{kg} / \mathrm{m}^{2}$ (26.7 vs. $\left.26.3 ; \mathrm{p}=0.843\right)$ and number of lymph nodes dissected (17.5 vs. $18.0 ; \mathrm{p}=0.691)$.

An association between physiotherapeutic stimulation and the positive progression of lymphatic flow was present in all three phases of the lymphoscintigraphic examinations. The images of the dynamic and static phases were more representative of the stimulation than the later whole body scan phase (Table I).

In the WPS group, a significant increase in the number of lymph nodes between the first and second whole body scan examination was observed $(\mathrm{p}=0.007)$. In the WOPS group, there was no significant difference between the medians $(\mathrm{p}=0.102)$ (Table II).

A significant increase in the velocity of the lymphatic flow between the first and second examination was observed in the WPS group compared to the WOPS group, as represented by the difference in the median angular coefficient ratio of the second examination compared to the first examination $(\mathrm{p}=0.014)$ (Table III).

Additional analysis of the drainage bundles in the upper limb showed a predominance of lymphatic flow progression through the cephalic bundle in both groups, which was intensified after physiotherapeutic stimulation. Progression through the basilic bundle as the only route was less frequent than progression through both bundles simultaneously (Table IV).

\section{Discussion}

With advances in breast cancer treatment and consequent increases in survival rates, quality of life has become a major concern for breast cancer patients (31). The occurrence of post-mastectomy lymphedema predisposes individuals to incapacitating diseases, with great socioeconomic impact $(10,16)$. Early diagnosis and intervention, such as skin care $(19,32)$, kinesiotherapy and self-massage $(12,18,19)$, may significantly reduce the incidence of complications (32). Research on improving quality of life has indicated that the prevention of lymphedema is the best strategy for breast cancer patients. Prior knowledge of normal lymphatic circulation and its changes in the presence of obstruction has directed techniques of physiotherapeutic stimulation. Various lymphatic drainage techniques have been used for stimulating lymphatic flow and treating lymphedema, such as those proposed by Vodder, Leduc and Földi. The technique proposed by Földi (23) was chosen for the present study, since it is routinely used at our institution.

Although several studies have used lymphoscintigraphy to document the behavior of lymphedema and to make before and after treatment comparisons (26-29), there is a lack of documentation regarding the immediate postoperative period. The effects of physiotherapeutic stimulation during this period motivated the present investigation. The aim of the study was to evaluate whether manual physiotherapeutic stimulation, which can easily be performed by patients themselves, might improve the progression of lymphatic flow.

We observed that the technique of early physiotherapeutic stimulation was effective regarding lymphatic flow progression in the WPS group compared with the WOPS group. In this respect, several authors have reported increased lymphatic transportation using the same procedure (33-36) among patients with established lymphedema.

As shown in Table I, all patients except one showed the progression of lymphatic flow to the lymph node chain, even if this occurred at a later stage. The one exception did not present progression even with stimulation; however, this patient had the greatest number of lymph nodes dissected $(\mathrm{n}=34)$. This finding is concordant with Clodius et al (9), who reported that the pathogenesis of the lymphedema is attributed to the presence of fewer lymphatics in the dissected area.

There are two common drainage routes in the upper limbs: the basilic route, which feeds into the axillary lymph nodes, and the cephalic route, in the apical lymph nodes. There are also two infrequent routes, the cervical and internal mammary routes $(30,37,38)$. The lymphatic vessels of the upper limbs flow out into the lymph nodes of the axillary region $(37,38)$, and therefore the basilic route is the principal drainage route. In the event of obstruction in the axillary region, the drainage route along the cephalic vein becomes important. This was observed in our study: patients in the WPS group showed this collateral route, while patients in the WOPS group did not.

As a strategy for stimulating lymphatic circulation in cases of the obstruction of normal lymphatic flow, alternative routes need to be considered, such as the cephalic route. Furthermore, anastomoses of the lymphatic capillaries need to be considered. These deviate lymphatic flow in a direction opposite to the normal course (38), thereby stimulating an 
alternative drainage route. In a systematic review, Moseley et al concluded that, although self-massage only promoted a small reduction in the volume of the limb, this was more beneficial than doing nothing for the swollen limb (35). Williams et al also reported that the technique was important when no treatment for lymphedema was available (18).

Considering that inflammation due to surgical aggression hinders the passage of lymphatic drainage (39) and causes increased limb volume, protein stagnation and the risk of complications, the findings from our study reinforce the need to stimulate early lymphatic drainage. Self-massage is a technique that is easy for patients to perform, and they should be given guidance in this respect by the professionals involved in rehabilitation.

\section{References}

1. National Cancer Institute (NCI), USA: Progress shown in death rates from four leading cancers: decline in overall mortality has slowed (monograph on the Internet). Available from: http://www. nci.nih.gov/newscenter/pressreleases/2003ReportRelease. Cited March 2004.

2. Instituto Nacional do Câncer (INCA): Estimativa 2008: incidência de câncer no Brasil. INCA, Rio de Janeiro, 2008.

3. Johansson S, Svensson H and Denekamp J: Dose response and latency for radiation-induced fibrosis, edema and neuropathy in breast cancer patients. Int J Radiot Oncol Biol Phys 52: 1207-1219, 2002.

4. Bergmann A, Mattos IE and Koifman RJ: Diagnóstico do linfedema: análise dos métodos empregados na avaliação do membro superior após linfadenectomia axilar para tratamento do câncer de mama. Rev Bras Canc 50: 311-320, 2004.

5. Bourgeois P, Leduc O and Leduc A: Imaging techniques in the management and prevention of posttherapeutic upper limb edemas. Cancer 83: 2805-2813, 1998.

6. Paci E, Cardiddi A, Bacilli A, et al: Long-term sequelae of breast. Tumori 82: 321-324, 1996.

7. Goffman TE, Laronga C, Wilson L and Elkins D: Lymphedema of the arm and breast in irradiated breast in cancer patients: risks in an era of dramatically changing axillary surgery. Breast $\mathbf{J} 10$ : 405-411, 2004.

8. Carpentier PH: Physiopathologie des lymphoedèmes. Rev Med Interne 23: S371-S374, 2002.

9. Clodius L, Piller NB and Casley-Smith JR: The problems of lymphatic microsurgery for lymphedema. Lymphology 14 69-76, 1981.

10. Filippetti M, Santoro E, Graziano F, Petric M and Rinaldi G: Modern therapeutic approaches to postmastectomy brachial lymphedema. Microsurgery 15: 604-610, 1994.

11. Glass EC, Essner R and Giuliano AE: Sentinel node localization in breast cancer. Semin Nucl Med 29: 57-68, 1999.

12. Didem K, Ufuk YS, Serdar S and Zümre A: The comparison of two different physiotherapy methods in treatment of lymphedema after breast surgery. Breast Cancer Res Treat 93: 49-54, 2005.

13. Roucout S and Oliveira VM: Etiologia, prevenção e tratamento do linfedema pós-mastectomia. Med Reab 49: 11-15, 1999.

14. Linnitt N: Lymphoedema: recognition, assessment and management. Br J Community Nurs 10: S20-S26, 2005.

15. Clodius L: Minimizing secondary arm lymphedema from axillary dissection. Lymphology 34: 106-110, 2001.

16. Bumpers HL, Best IM, Norman D and Weaver WL: Debilitating lymphedema of the upper extremity after treatment of breast cancer. Am J Clin Oncol 25: 365-367, 2002.
17. Rietman JS, Dijkstra PT, Geertzen JHB, et al: Treatment-related upper limb morbidity 1 year after sentinel lymph node biopsy or axillary lymph node dissection for stage I or II breast cancer. Ann Surg Oncol 11: 1018-1024, 2004.

18. Williams AF, Vadgama A, Franks PJ and Mortimer PS: A randomized controlled crossover study of manual lymphatic drainage therapy in women with breast cancer-related lymphoedema. Eur J Cancer Care 11: 254-261, 2002.

19. Rich A: How to care for uncomplicated skin and keep it free of complications. Br J Community Nurs 12: S6-S9, 2007.

20. Hampton S: Elvarex compression garments in the management of lymphoedema. Br J Nurs 12: 925-926, 928-929, 2003.

21. King B: Diagnosis and management of lymphoedema. Nurs Times 102: 47, 49, 51, 2006.

22. Camargo MC and Marx AG (eds): Linfoterapia. In: Reabilitação Física no Câncer de Mama. Editora Roca, São Paulo, pp98-99, 2000.

23. Földi E, Földi M and Weissleder H: Conservative treatment of lymphoedema of the limbs. Angiology 36: 171-180, 1985.

24. Szuba A, Shin WS, Strauss HW and Rockson S: The third circulation: radionuclide lymphoscintigraphy in the evaluation of lymphedema. J Nucl Med 44: 43-57, 2003.

25. Baulieu F, Baulieu JL, Secchi V, Dabiens J, Barsotti J and Itti R: Factorial analysis of dynamic lymphoscintigraphy in lower limb limphoedema. Nucl Med Comm 10: 109-119, 1989.

26. Ferrandez JC, Laroche JP, Serin D, Felix-Faure C and Vinot JM: Aspects lymphoscintigraphiques des eddets du drainage lymphatique manuel. J Mal Vasc 21: 283-289, 1996.

27. Perrymore WD and Harolds JA: Technetium-99m-Albumin Colloid Lymphoscintigraphy in postoperative lymphocele. J Nucl Med 37: 1517-1518, 1996.

28. Burnand KG, McGuinness CL, Lagattolla NR, Browse NL, El-Aradi A and Nunan T: Value of isotope lymphography in the diagnosis of lymphoedema of the leg. Br J Surg 89: 74-78, 2002.

29. Bull RH, Fenton DA and Mortimer PS: Lymphatic function in the yellow nail syndrome. Br J Dermatol 134: 307-312, 1996.

30. Macea JR and Fregnani JHTG: Anatomy of the thoracic wall, axilla and breast. Int J Morphol 24: 691-704, 2006.

31. Kwan W, Jackson J, Weir LM, Dingee C, McGregor G and Olivotto IA: Chronic arm morbidity after curative breast cancer treatment: prevalence and impact no quality of life. J Clin Oncol 20: 4242-4248, 2002.

32. Linnitt $\mathrm{N}$ : Complex skin changes in chronic oedemas. $\mathrm{Br} \mathrm{J}$ Community Nurs 12: S10-S15, 2007.

33. Badger C, Preston N, Seers K and Mortimer P: Physical therapies for reducing and controlling lymphoedema of the limbs. Cochrane Database Syst Rev: CD003141, 2004.

34. Huit M: A guide to treating lymphoedema. Nurs Times 96: 42-43, 2000.

35. Moseley AL, Carati CJ and Piller NB: A systematic review of common conservative therapies for arm lymphoedema secondary to breast cancer treatment. Ann Oncol 18: 639-646, 2007.

36. Andersen L, Hojris I, Erlandsen M and Andersen J: Treatment of breast-cancer related lymphedema with or without manual lymphatic drainage - a randomized study. Acta Oncol 39: 399-405, 2000.

37. Suami H, Pan WR and Taylor GI: Changes in the lymph structure of the upper limb after axillary dissection: radiographic and anatomical study in a human cadaver. Plast Reconstr Surg 120: 982-991, 2007.

38. Suami H, Pan WR and Taylor GI: The lymphatic territories of the upper limb: anatomical study and clinical implications. Plast Reconstr Surg 119: 1813-1822, 2007.

39. Tabibiazar R, Cheung L, Han J, et al: Inflammatory manifestations of experimental lymphatic insufficiency. PloS Med 3: 1114-1139, 2006. 